\title{
Proposed System for a Socio-technical Design Framework for Improved User Collaborations with Automation Technologies
}

\author{
Saadati, Parisa; Abdelnour-Nocera, José; Clemmensen, Torkil
}

Document Version

Final published version

Publication date:

2019

License

CC BY-NC-ND

Citation for published version (APA):

Saadati, P., Abdelnour-Nocera, J., \& Clemmensen, T. (2019). Proposed System for a Socio-technical Design Framework for Improved User Collaborations with Automation Technologies. Paper presented at The 17th IFIP TC.13 International Conference on Human-Computer Interaction. INTERACT 2019, Paphos, Cyprus.

Link to publication in CBS Research Portal

\footnotetext{
General rights

Copyright and moral rights for the publications made accessible in the public portal are retained by the authors and/or other copyright owners and it is a condition of accessing publications that users recognise and abide by the legal requirements associated with these rights.

Take down policy

If you believe that this document breaches copyright please contact us (research.lib@cbs.dk) providing details, and we will remove access to the work immediately and investigate your claim.
} 


\title{
Proposed System for a Socio-technical Design Framework for Improved User Collaborations with Automation Technologies
}

\author{
Parisa Saadati ${ }^{1}$, José Abdelnour-Nocera ${ }^{1}$ and Torkil Clemmensen ${ }^{2}$ [0000-0002-0934-2336] \\ ${ }^{1}$ University of West London, UK \\ parisa.saadati@uwl.ac.uk \\ ${ }^{2}$ University of West London and ITI/Larsys Portugal \\ abdejos@uwl.ac.uk \\ ${ }^{2}$ Copenhagen Business School \\ tc.digi@cbs.dk
}

\begin{abstract}
To improve human performance, interactive technolegies are going towards more automated systems that involve computers, robots and cyber-physical systems into the decisionmaking process. While automation can lead to increased performance and reduced impact of human errors, interactive technologies without optingaresesign can have a negative impact on the experience of operators and end-users, leading to suboptimal performance of the automated systems. In this research, we aim to evaluate and Yefine Human Work Interaction Design (HWID) framework to be applicable in various highy y automated settings including Industry 4.0 environments. This will be performed via a tharough literature review as the first step. The list of identified factors playing a potential role 1 various interactive systems will then be evaluated and optimised in three case studies 1 towill try to understand how to maximise collaborations between the users and the machipe In interactive systems. A practical approach for evaluating both employees' and end-users Rerspectives in three scenarios with different levels of automation will be assessed. The ultimate output of the study will be a framework or model that will help in designing future research studies for semi-autonomous systems that involve high levels of interaction betweenusers and the machine. We expect that the framework output of this research will provide a comprensive guideline applicable to many Industry 4.0 technologies.
\end{abstract}

Keywords: sociotechnical, human work interaction design, automation, augmentation, Industry 4.0 .

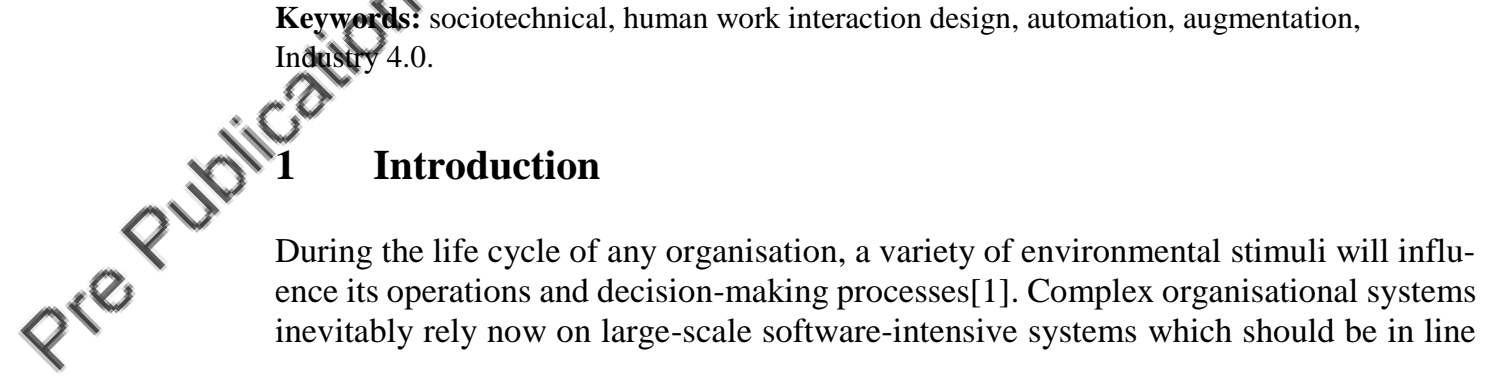


with the organisational goals and strategies. In this paper, we hint at a possible sociotechnical HCI framework, with customized value propositions and a case presentation for a future investigation of three different scenarios with different levels of automation.

Socio-Technical System Design (STSD) developments have identified and addressed several problems in understanding and developing complex systems. Despite many positive outcomes, these methods have not materially changed industrial software engineering practices due to involving users only in the testing stage of any new system development instead of the design process[2].

Currently, 'automation' is one of the main means for supporting operators using sy tems that feature high complexity. Automation allows designers to transfer the burdem from operators to machine by re-allocating the system tasks that were previous loerformed by human[3]. Several researchers have studied different aspects of implementation of advanced interactive technologies employing automation in different platforms[1, 3-7].

Organisations can now improve operations and decision making by implementing cyber-physical systems (CPS) and internet of things (IoT), and potentially linking them to blockchain technology in the future. Rising integration of noternet of Everything (IoE) into the industrial value chain is the foundation of "Indestry 4.0" technologies[8]. These technologies can improve the end-users' experience be does not necessarily and automatically guarantee a positive response from workers and customers[9]. Hence, developments towards future 'smart workplaces' need to be carefully designed in order to achieve expected service quality goals for both ond-users and employees. The main purpose of this study is to identify all humanishe/social and technological elements in the design of newly automated systems aptidable to Industry 4.0 that are affecting the human and machine collaborations. This paper is organised in two sections as follows; Section 2 introduces the findings of the fiterature review on different factors affecting the human and machine collaborations and categorising them into three main categories. Section 3 proposes the futa research outcome by investigating into these factors from three case studies; university library, research platform and an airport.

\section{Review}

Replacing humgh habits with automated interactive systems requires consideration of potential hanges on human activity and the new coordination demands on the human operators These experiences highly depend on the type and level of automation [7] and to what extent the developer has allowed the machine to make decisions.

\subsection{Technological elements of interactive systems}

The fourth industrial revolution (Industry 4.0) which is now undergoing, will transform the design, manufacturing, and operation of various products and systems.[7] The increasing integration of the IoE into the industrial value chain has built the foundation for this revolution.[8] The increased connectivity and interaction among systems, humans and machines support the integration of various automated or semi-automated 
systems, and hence, increasing flexibility and productivity [10]. These automated systems will lead to interconnected manufacturing systems and supply chains with their own challenges.

To achieve sufficient autonomous awareness in a system, efficient integration of smart sensors and mobile devices is required alongside industrial communication protocols and standards. Economic impact of this industrial revolution is supposed to be huge and comes with changes in the existing business models[10-12].

Industry 4.0 advancements [7] are categorised into four main principles in general; technical assistance, interconnections, decentralised decisions, and information trans parency. "Collaborations" is a sub-principle of the "Interconnections" principle (which includes Collaborations, Standards and Security). Three type of collaborations are Considered in the context of Industry 4.0: human-human, human-machine and machinemachine collaborations. Main focus of this research is to improve the guidelines for human-machine collaborations.

\subsection{Human Work Interaction Design}

Human Work Interaction Design (HWID) is a comprehehsile framework that aims to establish relationships between extensive empirical work-domain studies and HCI designs. It builds on the foundation of Cognitive Wolk Analysis (CWA).[5] HWID is currently positioned as a modern lightweight version of CWA.

HWID studies how to understand, conceptralise, and design for the complex and emergent contexts in which information communication technologies (ICT) and work are entangled.[1] HWID models ane based on the characteristics of humans and work domain contents and the interactions during their tasks and decision making activities (Figure 1). HWID focuses of the integration of work analysis (i.e. CWA methods) and interaction design mathods (e.g. goal-oriented design and HCI usability) for smart workplaces. The ultimate goal of HWID is to empower users by designing smarter workplaces in 4 ifious work domains.

For applying HWID models to specific workplaces we need to consider several independent and entangled factors [5]. Considering numerous theories, concepts, techniques and metheds developed for other work environments is the first step. Environmental contexts such as national, cultural, geographic, social and organisational factors will haye an important role in designing optimal HWID models, as they impact interaction between users (i.e. both operators and employees) and smart systems in their work and life. There are more work-related factors including the users' how wledge/skills, application domain, work contents and goals, as well as the nature of lasks or newly introduced technologies to be considered in the interaction performance.

\subsection{Humanistic elements of interactive systems}

To address human element in designing complex interactive systems, design fiction and design ethnography should be linked [16]. This is in line with considering the impact of anthropology on the design's future-orientedness by understanding the cultural 
meanings and sensitivity to values and context [17]. Analysis of the allocation of functions is necessary to identify the optimal distribution of both functions and tasks between a partly-autonomous system and the user [3].

Physical support of human workers by robots or machines is an important aspect of new technologies. This is due to involvement of users in conducting a range of tasks that are unpleasant, too exhausting or unsafe.[18,19] For an effective, successful, and safe support of users in physical tasks, it is necessary that robots or machines interact smoothly and intuitively with their human counterparts [18], and that humans are properly trained for this kind of human-machine collaboration.[8]

The value of information. In collaborations between human and machine, the value of information is now more recognised given high power of the machine (ndecisionmaking in highly-automated systems. For instance, informing users about the sensor's reading power of Tesla's automated car can significantly increasedeif rust.[6] However, other studies show that the number of information items of asks users receive in an automated process should be personalised and up to the poinfof their desire/tolerability. Not enough functions allocated to a user will lead tounderload and boredom and thus decreased performance.[20] Too many allocated functions will lead to cognitive, perceptive or motoric overload and increase negatiwe emotions (e.g. stress, anxiety) [21] and user's error.[20,3] Meanwhile, users car cope with emotions after spending some time with the autonomous technology andrefeloping some routines.

Providing an abundance of information ald ransparency is an important hypothesis in interactive technologies. Trust, transpaaency and acceptance of losing control (i.e. shared authority between the user and (system [8]) can improve the interaction of the user by revealing the ambiguous feetings toward the automation. Other psychological factors under study include worries bout practical challenges and security of the technology (e.g. hacking a system) and reliability of the process itself (e.g. flat mobile phone battery for systemsthat rely on applications). Users may lose their trust in decision-making of an autonated system when other humans who won't follow the same process are involved and can impact on the outcome. Another important situation is when responsibilities are shared between users and the system. Ability to identify responsible party erated to a bad outcome (i.e. user error versus system failure) can impact the performance of users [9]. Controllable designed interface and environment of work, asyell as feeling safe while using new technologies, are among other factors that can ircease the performance of the users.

Thvolving users in the design process. The design process should determine the content and format of information to be shared with users in order to create an experience of certainty and trust. The right amount and format of feedback from the users plays a major role for designing such systems. Motivating the users to engage with the new technologies is still a challenge due to lack of understanding of the end-users' individual experience and interaction with such technologies. Users can have different roles or backgrounds that can affect their discovery, collaboration and learning of the interactive system [11]. In some studies researchers have tried to recruit users for testing their 
interaction via use of flyers or instructions explaining the technology (a process known as augmentation)[22].

Furthermore, engaging users in designing the automated or augmented product will change their interaction time. It is recommended that the developing teams need to familiarise themselves with space and environment of practices, build trust with the employees and improve design ideas. Some of the studies suggested the relations between modes of discovery, design improvements, interaction and socio-spatial aspects. These relations can be developed more as an analytical and design tool to redefine the borders of opportunities for social interaction in daily automated spaces.

\section{Proposed further research}

For investigating independent and entangled factors related to human and machine collaborations in automated systems, we propose a practical approack for evaluating both end-users' and employees' (or operators') perspectives in an autongtous environment.

First step (current stage) in this research is to produce a list of relevant factors from different sources including: review of the relevant literature, contact and interview with experts in this domain, and observation of some smart workplaces. This comprehensive list will then be evaluated and optimised in two scerarios (University of west London library and mKRISHI® research platform). These scenarios were selected carefully based on potentially important factors such asocio-behavioural (e.g. work pattern), psychological (e.g. trust in system), demogahnical (e.g. wealth and ethnicity), and geographical characteristics of their user populations.

We will analyse previously-availab e (via literature review and expert opinions) and newly-gathered data (via questiongarres and interviews) to produce a model to be validated on scenario 3 settings (i.o. London based airport). By several iterations in this highly-automated environment we will refine and provide the final output of the study, which will be a tool/guideling for designing HWID models for various interactive technologies. Given the variety of environments and different levels of automation, we will potentially achieve different lists of factors that affect the performance of users. In the final scenario, current shortcomings and future opportunities will be evaluated by using an HWID model for future smart workplaces using Industry 4.0 framework.

\section{$U^{-1}$ \\ Conclusion}

In summary, the overall objective of this paper was to present a review of the possible theoretical background for a to-be-developed sociotechnical HCI framework, including customized value propositions for the work domain of choice, and, finally, to present three scenarios to be considered in future research. One of the outcomes that the current stage is a comprehensive list categorises in main principle and number of sub-principles of the factors impact the machine and human counterpart collaboration from sociotechnical perspective. This is what we hoped to illustrate with this paper as start of a series of papers in different scenarios with various automation level. 


\section{References}

1. Barricelli, B.R., Roto, V., Clemmensen, T., Campos, P., Lopes, A., Goncalves, F., Abdelnour-Nocera, J. (2018) Human Work Interaction Design 2018. Designing Engaging Automation. IFIP AICT 554, pp.215-228. http://doi.org/10.1007/978-3-030-05297-3_15

2. Baxter, G. and Sommerville, I. (2011) 'Socio-technical systems: From design methods to systems engineering', Interacting with Computers, 23(1), pp.4-17. https://doi: 10.1016/j.intcom.2010.07.003

3. Barricelli, B.R., Roto, V., Clemmensen, T., Campos, P., Lopes, A., Goncalves, F., Abdelnour-Nocera, J. (2018) Human Work Interaction Design 2018. Designing Engaging Automation. IFIP AICT 554, pp.36-56. http://doi.org/10.1007/978-3-030-05297-3_3 W

4. Abdelnour-Nocera J, Oussena S, Burns C (2015). Human Work Interaction Design of the Smart University. 4th IFIP 13.6 Working Conference on Human Work Interaction Design, AICT-468: pp.127-140

5. Clemmensen T (2011) A Human Work Interaction Design (HWID) Case Study in E-Government and Public Information Systems. International Journal of Public Information Systems 3: pp.105-113

6. Murat Dikmen and Catherine Burns. (2017) Trust in Autonomous Vehicles. 2017 IEEE International Conference on Systems, Man, and Cybernetics: pp.1093-1098. https://doi.org/10.1109/SMC.2017.8122757 (

7. Parasuraman, R., Sheridan, T., Wickens, C. (2000) A model for types and level of human interaction with automation. IEEE Transactions on Systems, Man, and Cybernetics - Part A:System and Humans, 30(3), pp.286-297

8. Hermann, M., Pentek, T. and Otto, B. (2016) Design Principles for Industrie 4.0 Scenarios. IEEE, pp. 3928-3937. http://doi.10.1109/HICSS.2016.48

9. World Economic Forum. (2018) The fourth Industrial Revolution, https://www.weforum.org/pages/the-fourth-industrial-revolution-by-klaus-schwab, last accessed 22nd August, 2018

10. Davies, R. (2015) Industry 4.0: Digitalisation for productivity and growth. European Parliamentary Research Service

11. Eric Lesser and Larry Prusak. (1999) Communities of Practice, Social Capital and Organizational Knowledge. Information Systems Review 1, pp.3-10. [Online] Available from: http://providersedge.com/docs/km_articles/Cop_-_Social_Capital_-_Org_K.pdf, last accessed 25th Feb, 2019

12. International Airport reviews, [Online] Available from: https://www.internationalairportreview.com/article/25929/personalisation-smart-airport/, last accessed 18th Feb, 2019

13. Joseph Lindley, Dhruv Sharma, and Robert Potts. (2014) Anticipatory Ethnography: Design Fiction as an Input to Design Ethnography. Ethnographic Praxis in Industry Conference Proceedings 2014, pp.237-253. https://doi.org/10.1111/1559-8918.01030

14. Ton Otto and Rachel Charlotte Smith. (2013) Design Anthropology: A Distinct Style of Knowing. In Design Anthropology: Theory and Practice, Wendy Gunn, Ton Otto and Rachel Charlotte Smith (eds.). Bloomsbury, London, New York, pp.1-29. https://doi.org/10.1017/CBO9781107415324.004

15. M.awais, D.Henrich, (2013) "Human- Robot Interaction in an Unknown Human Intention Scenario", 11th International Conference on Frontiers of Information Technology, 2013, pp. 89-94

16. S.Kiesler, and P.Hinds, (2004) "Human-Robot Interaction", Human-Computer Interaction, Volume 19, 2004 
17. Yerkes, RM., Dodson, J.D. (1908) The relation of strength of stimulus to rapidly of habitformation. Journal of Comparative Neurology and psychology, 18(5), pp.459-482.

18. Kirk, A. Brown,D.F. (2003) Employee assistance programs: A review of the management of stress and wellbeing through workplace counselling and consulting, Australian Psychologist 38(2), pp.138-143.

Wouters, N., Downs, J., Harrop, M., Cox, T., Oliveira, E., Webber, S., Vetere, F., Vande moere, A. (2016). Uncovering the Honeypot Effect: How Audiences Engage with Public Interactive Systems. Proceedings of the 2016 ACM Conference on Designing Interactive Systems (DIS '16), ACM, pp.5-16. http://doi.org/10.1145/2901790.2901796 